Research Article

\title{
Nanomaterial-Based Carbon Paste Electrodes for Voltammetric Determination of Naproxen in Presence of Its Degradation Products
}

\author{
Hassan A. M. Hendawy (D), ${ }^{1}$ Waheed M. Salem, ${ }^{2}$ Mahmmoud S. Abd-Elmonem, ${ }^{1}$ \\ and Elmorsy Khaled $\mathbb{D}^{3}$ \\ ${ }^{1}$ National Organization for Drug Control and Research (NODCAR), P.O. Box 29, Cairo, Egypt \\ ${ }^{2}$ Chemistry Department, Faculty of Science, Damanhour University, Damanhour, Egypt \\ ${ }^{3}$ Microanalysis Laboratory, Applied Organic Chemistry Department, National Research Centre, El Bohouth St., \\ Dokki, 12622 Giza, Egypt
}

Correspondence should be addressed to Elmorsy Khaled; elmorsykhaled@yahoo.com

Received 18 November 2018; Revised 12 February 2019; Accepted 1 April 2019; Published 16 April 2019

Academic Editor: Ricardo Jorgensen Cassella

Copyright (C) 2019 Hassan A. M. Hendawy et al. This is an open access article distributed under the Creative Commons Attribution License, which permits unrestricted use, distribution, and reproduction in any medium, provided the original work is properly cited.

\begin{abstract}
The present work describes a novel, simple, and fast electroanalytical methodology for naproxen (NAP) determination in pharmaceutical formulations and biological fluids in the presence of its degradation products. Carbon paste electrodes (CPEs) modified with different carbon nanomaterials, namely, glassy carbon powder (GCE), multiwall carbon nanotubes (MWCNTs), single-walled carbon nanotubes (SWCNTs), graphene nanosheets ( $\mathrm{Gr}$ ), and graphene oxides (GO) were tested. Comprehensive studies were performed on the electrode matrix composition including the nature of the pasting liquids, $\mathrm{pH}$, carbon nanomaterials, and mode of electrode modification. Two anodic oxidation peaks were recorded at 0.890 and $1.18 \mathrm{~V} \mathrm{in} 1 \times 10^{-1} \mathrm{~mol} \cdot \mathrm{L}^{-1}$ phosphate buffer solution at $\mathrm{pH}$ 6. Oxidation of naproxen (NAP) is an irreversible diffusion-controlled process. Calibration plots were rectilinear in the concentration ranging from 0.067 to $1.0 \mu \mathrm{g} \cdot \mathrm{mL}^{-1}$ with correlation coefficient 0.9979 . Photodegradation of NAP resulted in disappearance of the oxidation peak at $1.18 \mathrm{~V}$, allowing simultaneous determination of NAP in presence of its degradation product. The achieved high sensitivity and selectivity suggest the application of the proposed protocol for naproxen determination in pharmaceutical preparations and human blood plasma.
\end{abstract}

\section{Introduction}

Naproxen, 2-(6-methoxynaphthalen-2-yl) propanoic acid, is a nonsteroidal anti-inflammatory drug (NSAID) commonly used for the treatment of moderate and severe pain, fever, inflammation, and stiffness $[1,2]$ through inhabitation of both COX-1 and COX-2 enzymes that cause inflammation and pain in the body [3]. Moreover, NAP is suggested in case of rheumatoid arthritis and other inflammatory rheumatic diseases $[4,5]$.

Determination of NAP in pharmaceutical formulations and biological fluids has been proposed by applying spectrophotometric $[6,7]$, spectrofluorimetric $[8,9]$, capillary isotachophoretic [10], and high-performance liquidchromatographic methods coupled with spectrophotometric [11], amperometric [12], or mass spectrometric detectors [4].

The aforementioned techniques are demandingly laborious and time-consuming and require ancillary instrumentation. Samples prior to derivatization and the use of organic solvents are some of the inherent disadvantages. Electrochemical methods are effective tools for the determination of pharmaceutical compounds as they are faster, cheaper, easier, and more sensitive than spectrometric and HPLC methods. Several reports and comprehensive reviews about voltammetric methods for quantification of drugs have been found in the literature [13-17]. 
Naproxen has been determined voltammetrically by applying mercury electrodes for the cathodic reduction of NAP [18]; however, mercury electrodes have some limitations as they are toxic and there is rapid deterioration of the electrode response. Alternatively, Pt electrodes were suggested for anodic oxidation of naproxen [19]; the high background current with limited sensitivity and reproducibility due to contamination by the fouling products and impurities was reported [20]. Recently, other electrode materials were applied including boron-doped diamond [21, 22], gold electrode [23], glassy carbon [24], graphite electrode $[25,26]$, multiwall carbon nanotube-modified glassy carbon electrode (MWCNTs/GCE) [27, 28], and carbon paste electrodes modified with different nanomaterials [29-31] were reported.

Herein, the differential pulse voltammetric protocol for determination of naproxen in pharmaceutical formulations and biological fluids in presence of its degradation product using carbon paste electrodes modified with different nanomaterials has been suggested.

\section{Experimental}

2.1. Reagents and Chemicals. Ultrapure water with electric resistivity $\sim 18.3 \mathrm{M} \Omega \cdot \mathrm{cm}$ (Milli-Q system, Millipore) was used for preparing supporting electrolytes and stock solutions. Britton-Robinson buffer was prepared, and the desired $\mathrm{pH}$ value was adjusted with the appropriate amount of $2 \times 10^{-1} \mathrm{~mol} \cdot \mathrm{L}^{-1} \mathrm{NaOH}$ solution.

Graphite powder (synthetic 1-2 mm, Aldrich) or glassy carbon powder (GC, "Sigradur-G” type, HTW Meitingen, Germany) was used for electrode fabrication. Different carbon nanaomaterials including multiwall carbon nanotubes (MWCNTs, Aldrich), single-walled carbon nanotubes (SWCNTs, Aldrich), graphene nanosheets (Gr, Sigma), and graphene oxides (GO, Sigma) were tested. Paraffin oil (PO; Merk, Germany), silicone oil (SO; Sigma Aldrich), or tricresyl phosphate (TCP, Fluka) were applied as pasting liquids.

2.2. Authentic Samples. An authentic sample of naproxen $\left(\mathrm{C}_{14} \mathrm{H}_{14} \mathrm{O}_{3}, 230.259 \mathrm{~g} \cdot \mathrm{mol}^{-1}\right)$ was obtained from the $\mathrm{Na}$ tional Organization for Drug Control and Research, Giza, Egypt. The stock drug solution $\left(1 \times 10^{-4} \mathrm{~mol} \cdot \mathrm{L}^{-1}\right)$ was freshly prepared by dissolving the appropriate amounts of NAP in $10^{-2} \mathrm{~mol} \cdot \mathrm{L}^{-1} \mathrm{NaOH}$ solution.

2.3. Pharmaceutical Preparation. Naprosyn tablets ( $250 \mathrm{mg}$ NAP/tablet; Egyptian Group for Pharmaceutical Industries, Cairo, Egypt) were purchased from local drug stores. One tablet was grinded and dissolved in $50 \mathrm{~mL} \mathrm{NaOH}$ solution. Naproxen content was assayed according to the proposed and HPLC methods [32].

2.4. Biological Samples. Aliquots of the biological fluid (plasma, obtained from a healthy male) were spiked with different NAP concentrations, treated with $0.1 \mathrm{~mL}$ of $70 \%$ perchloric acid diluted to $10 \mathrm{~mL}$, vortexed for $1.0 \mathrm{~min}$, and centrifuged for $10 \mathrm{~min}$ at $13000 \mathrm{rpm}$. The supernatants were neutralized with $\mathrm{NaOH}$ to the appropriate $\mathrm{pH}$ value, and the volume was completed to $25 \mathrm{~mL}$ with water.

2.5. Apparatus. All voltammetric experiments were carried out using a Metrohm computrace voltammetric analyzer model 797 VA with software version 1.0 (Metrohm, Switzerland) equipped with $\mathrm{Ag} / \mathrm{AgCl}\left(3 \mathrm{~mol} \cdot \mathrm{L}^{-1} \mathrm{KCl}\right)$ and platinum electrodes as reference and auxiliary electrodes, respectively. The $\mathrm{pH}$ measurements were carried out using a $692 \mathrm{pH}$ meter (Metrohm, Herisau, Switzerland) with a combined pH glass electrode (6.0202.100).

The working carbon paste electrodes were prepared by mixing $0.5 \mathrm{~g}$ of carbon materials (either graphite powder or GC) with $0.2 \mathrm{~g}$ of paraffin oil in a ceramic mortar for $15 \mathrm{~min}$. Alternatively, $10 \%$ of carbon powder was replaced with different nanomaterial, and the paste was prepared by the same manner. Homogenous carbon pastes were pushed into the individual Teflon piston holders with conductive electric wires for electric contact with a potentiostat [33]. Electrode surface regeneration was performed via polishing with a wet filter paper.

For surface modification, $20 \mu \mathrm{L}$ of the nanomaterial suspension $\left(2 \mathrm{mg} \cdot \mathrm{mL}^{-1}\right.$ in DMF) was drop-casted on inverted CPEs (graphite/PO matrix) and left to dry for $24 \mathrm{~h}$ at $25^{\circ} \mathrm{C}$. The modified CPEs were rinsed with deionized water and used directly in the electrochemical cell.

2.6. Procedures. An appropriate volume of the NAP stock solution was added to $15 \mathrm{~mL}$ of Britton-Robinson buffer at the desired $\mathrm{pH}$ value. The voltammograms were recorded using differential pulse voltammetry (DPV), with the following parameters: pulse height, $+50 \mathrm{mV}$; pause before scan, $2 \mathrm{~s}$; pulse width, $100 \mathrm{~ms}$; pulse time, $40 \mathrm{~ms}$; and scan rate, $40 \mathrm{mV} \cdot \mathrm{s}^{-1}$.

\section{Results and Discussion}

3.1. Electrochemical Oxidation of Naproxen. The electrochemical behavior of NAP on blank carbon paste electrodes was evaluated by applying cyclic voltammetry and differential pulse voltammetry at $\mathrm{pH} 6$ (Figure 1). Under $\mathrm{CV}$ conditions, the anodic peak at $0.999 \mathrm{~V}$ corresponds to naproxen oxidation with the formation of an intermediate carboxylic radical, followed by decarboxylation. The second anodic peak appeared at $1.249 \mathrm{~V}$ corresponding to another current maximum that possibly belongs to ketone (2-acetyl6-methoxynaphthalene, AMN), which in agreement with more recent voltammetric studies discussed two oneelectron transfers in oxidation of NAP in aqueous media $[24,26,34,35]$. No cathodic peaks were recorded indicating the irreversibility of naproxen oxidation over the carbon paste electrode, the working electrode.

Differential pulse voltammetry showed sharp and welldefined peaks at 0.976 and $1.221 \mathrm{~V}$ with an improved peak height compared with $\mathrm{CV}$; therefore, further studies related to the quantitative determination of naproxen were carried 


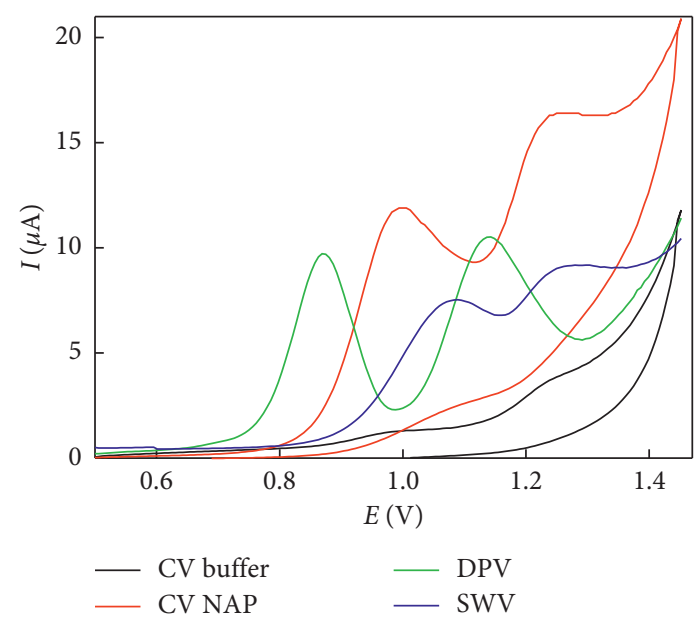

FIGURE 1: Voltammetric behavior of naproxen on the carbon paste electrode surface in $2 \times 10^{-1} \mathrm{~mol} \cdot \mathrm{L}^{-1}$ phosphate buffer solution at $\mathrm{pH}$ 6. The scan rate employed was $50 \mathrm{mV} \cdot \mathrm{s}^{-1}$ and NAP concentration $3.0 \mu \mathrm{g}$

out using the DPV technique. It is noteworthy to mention that the square wave voltammetric technique showed two peaks at 1.06 and $1.25 \mathrm{~V}$ but with lower peak height compared with DPV.

\subsection{Optimization of Electrode Matrix Compositions. The} experimental conditions were optimized for the NAP electrochemical response in order to achieve the highest analytical performance. Thus, the effect of electrode matrix compositions, $\mathrm{pH}$ of the supporting electrolyte, and electrochemical parameters were studied and optimized.

3.2.1. Effect of Pasting Liquid and Working $p H$ Range. NAP is considered as a NSAID of the propionic acid group with a $\mathrm{pKa}$ value of 4.15 [36]. At higher $\mathrm{pH}$ values, naproxen is completely deprotonated and thus an uncharged radical would be formed during the first electrochemical oxidation process, followed by decarboxylation [27]. The second oneelectron transfer may involve the formation of a cation that is stabilized by the methoxynaphthyl ring through resonance structures.

Silicon oil showed a wide working $\mathrm{pH}$ range from 3 to 8 with the optimum at $\mathrm{pH} 4$ (S1). On the contrary, the peaks obtained using TCP as a pasting liquid were very poor and will be ignored in the following experiments (Figure 2(a)).

Application of the paraffin oil as pasting liquids showed improved peak heights with the shift of the second oxidation peak by about $50 \mathrm{mV}$ compared with silicon oil-based electrodes. Moreover, the electrochemical oxidation of $\mathrm{NAP}$ at $\mathrm{CPE} / \mathrm{PO}$ electrodes was investigated at different $\mathrm{pH}$ values ranging between 2.0 and 10.0 (Figure 2(b)). The peak potentials $\left(E_{\mathrm{p}}\right)$ of both NAP oxidation peaks were shifted toward less positive oxidation potentials via increasing $\mathrm{pH}$ value, indicating the electrode reaction is governed by a proton transfer process. The relationship between the peak potential and the $\mathrm{pH}$ value of the solution was evaluated as $E_{\mathrm{p} 1}(\mathrm{~V})=1.2895-0.0127 \mathrm{pH}, r^{2}=0.9694$ and $E_{\mathrm{p} 2}(\mathrm{~V})=$ $1.1068-0.0195 \mathrm{pH}, r^{2}=0.9143$ (Figure 2(c)). The maximum peak height of both oxidation peaks was recorded at $\mathrm{pH}$, which will be selected for the following studies.

\subsubsection{Nanomaterial Impact on Sensor Performance}

(1) Bulk-Modified Electrodes. Nanostructure-modified electrodes have been adopted as a promising approach to facilitate the direct electron transfer of biomolecules and improving the electrode performance. Herein, the traditional graphite powder usually applied for fabrication of carbon paste electrodes was completely replaced by glassy carbon powder (GC) and MWCNTs or graphene. Alternatively, $10 \%$ incorporation of nanomaterials with the carbon paste matrix was also tested.

Using $\mathrm{NaOH}$ as a solvent for NAP, carbon paste electrodes showed two irreversible oxidation peaks for NAP at 0.880 and $1.14 \mathrm{~V}$, respectively (Figure 3(a)). Glassy carbon powder-based electrodes showed better performance compared with graphite/CPE. However, complete replacement with MWCNTs or graphene showed complete disappearance of the oxidation peaks which may be attributed to the high hydrophobicity of the carbon nanotubes.

Different performances were achieved by replacing $10 \%$ of the graphite powder with different nanomaterials (Figure 3(a)). SWCNT-incorporated electrodes showed the best performance with two well-defined peaks at 0.856 and $1.14 \mathrm{~V}$, respectively. Even graphene oxide (GO) provides improved first oxidation peak at $0.833 \mathrm{~V}$; the second one at 1.2 V was broader than that of SWCNTs. Similar to graphene oxide, MWCNTs showed a well-defined peak at lower oxidation potential $(0.790 \mathrm{~V})$ with an improved peak height compared with CPE and a broad peak at $1.11 \mathrm{~V}$.

On application of methanol as solvent for NAP (Figure 3(b)), the tested materials showed different behavior where graphene oxide was the best followed by SWCNTs and glassy carbon powder. The first oxidation peak was recorded at $0.869,0.875,0.821$, and 0.803 for GO, SWCNTS, GC, and MWCNTs, respectively.

The effect of the nanomaterial within the electrode matrix was investigated by varying the SWCNT content from 2.5 to $20 \%$, and $10 \%$ was the most promising.

(2) Surface-Modified Electrodes. Based on the previous notification of the effect of carbon nanomaterials, an alternative approach for improving the electrode performance can be attributed via modification of the working electrode surface by drop-casting of nanomaterial solution in DMF $\left(2 \mathrm{mg} \cdot \mathrm{mL}^{-1}\right)$ on the electrode surface. After drying and evaporation of the organic solvent, thin layers of the carbon nanomaterials were deposited on the electrode surface on which the oxidation of the target analyte takes place.

According to the voltammetric peaks represented in Figure 3(c), SWCNTs showed the best performance compared with other nanomaterials tested. In $\mathrm{NaOH}$ medium, no noticeable shifting in the peak potential was observed, while in methanol, SWCNTs showed higher peak height with shifting toward more positive potential.

The remarkable enhancement in current response and shifting of the peak potential provide clear evidence of the 


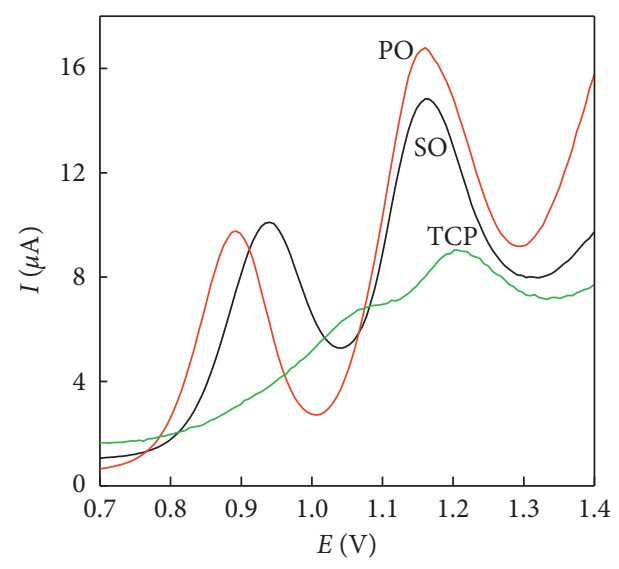

(a)

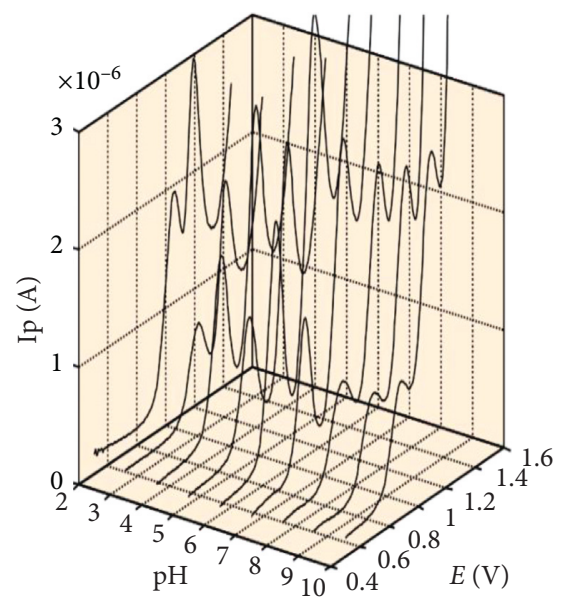

(b)

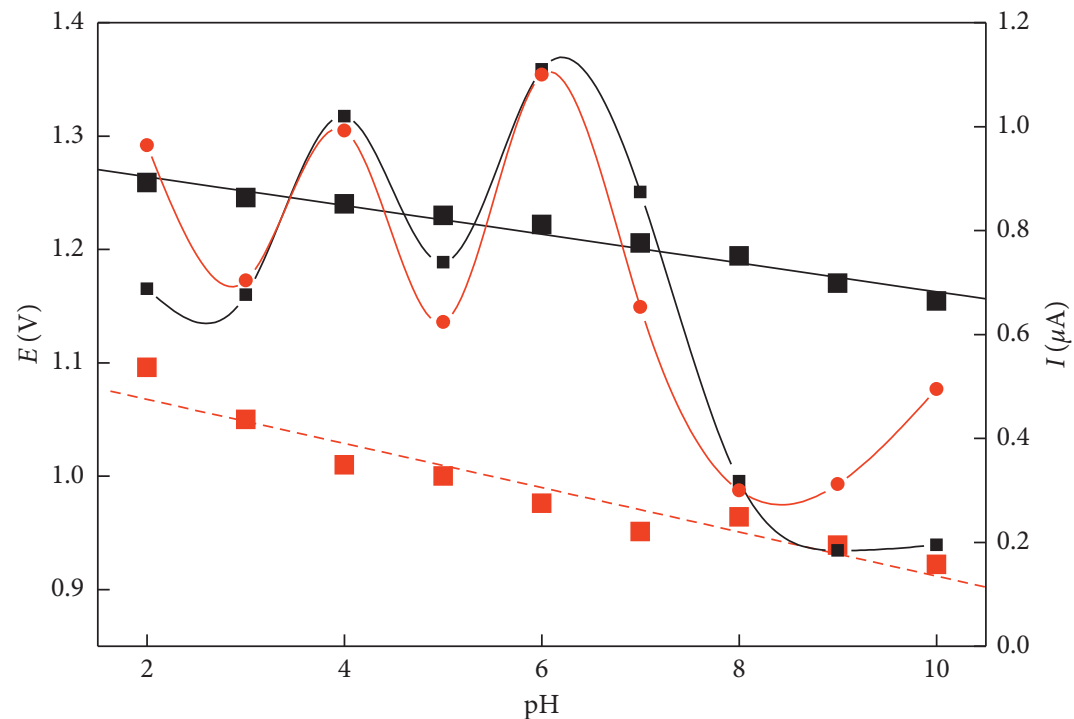

(c)

Peak 1

Peak 2

Figure 2: Differential pulse voltammograms for $4.5 \mu \mathrm{g}$ NAP (a) using different pasting liquids, (b) at different $\mathrm{pH}$ values, and (c) peak potential and peak currents at different $\mathrm{pH}$ values. The scan rate employed was $50 \mathrm{mV} \cdot \mathrm{s}^{-1}$.

catalytic effect of the nanomaterial-modified carbon paste electrode which acts as a promoter to enhance the electrochemical reaction, considerably accelerating the rate of electron transfer. Indicative of a mass transport regime that includes a thin-layer diffusional process (entrapment of naproxen species within the carbon nanotube film) is presented as a possible explanation for the lowered oxidation potential and substantial current increase. Moreover, the methoxynaphthyl ring in naproxen may interact strongly with the carbon nanotube structure through $\pi-\pi$ bonds $[37,38]$. Therefore, instead of only considering the change of mass transfer regime of NAP species, this strong interaction may contribute for the voltammetry profile and higher current increase for NAP presented.

3.2.3. Electrode Surface Poisoning. The voltammetric recording for consecutive measurements of NAP on the native carbon paste electrode resulted in a constant decrease in current and shifting of both oxidation peaks toward more positive potential, which may be attributed to the adsorptive properties of NAP or its oxidation products on the electrode surface (Figure 4(a)). Modification with nanomaterials enhances the electrode performance and diminishes the electrode poisoning, which indicates that carbon nanotubes provided antifouling properties probably due to faster electron kinetics (Figure 4(b)).

In agreement with these results, it is established the hypothesis that some of the naproxen oxidation products become adsorbed at the electrode surface $[19,21,24]$ and that through controlled oxidation, it is possible to "saturate" the surface of the electrode, thus obtaining constant signals that improve the repeatability of analyses.

3.3. Effect of Scan Rate. Oxidation of naproxen was carried out at different scan rates ranging between 20 and $300 \mathrm{mV} \cdot \mathrm{s}^{-1}$ (Figure 5). The peak potential and the 

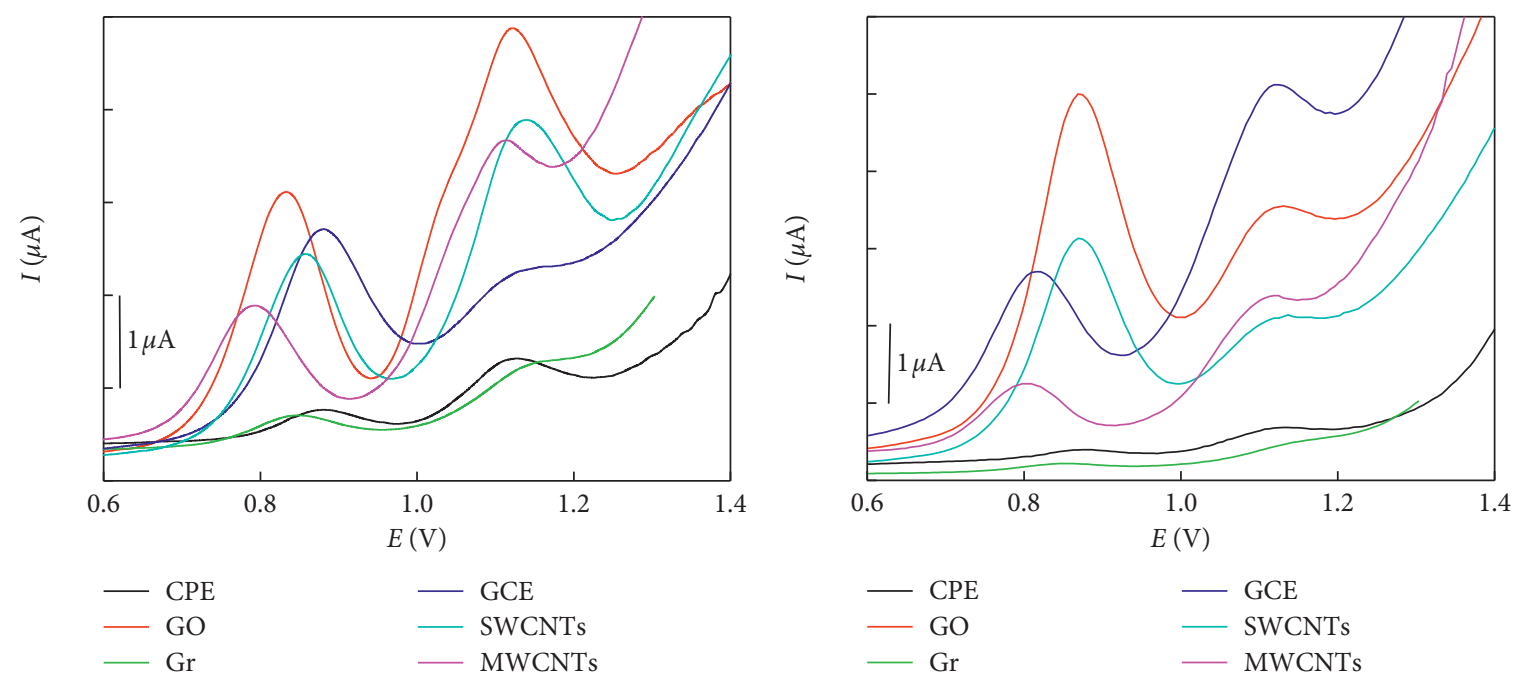

(a)

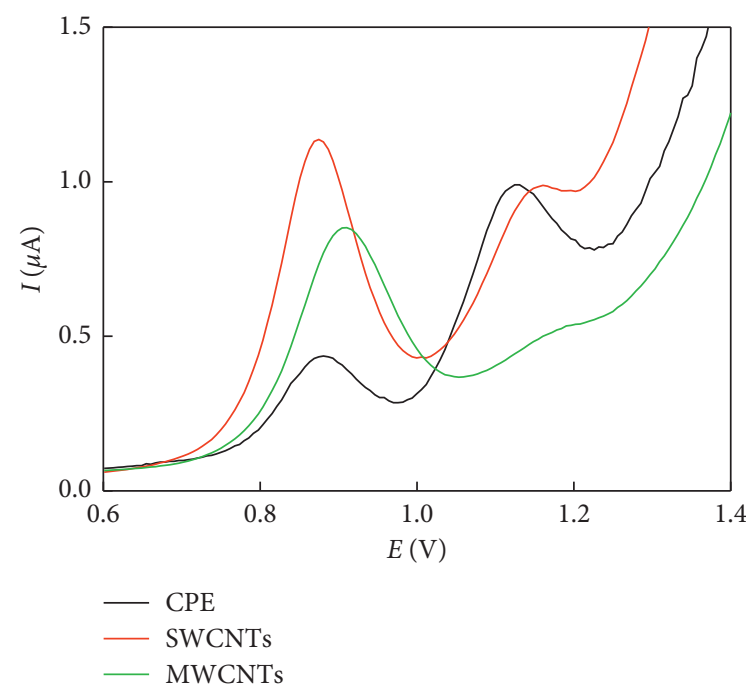

(c)

(d)

FIGURE 3: Differential pulse voltammograms of NAP using carbon paste electrodes modified in bulk and surface with different nanomaterials $(a, c)$ dissolved in $\mathrm{NaOH}$ and $(b, d)$ dissolved in methanol. The scan rate employed was $50 \mathrm{mV} \cdot \mathrm{s}^{-1}$.

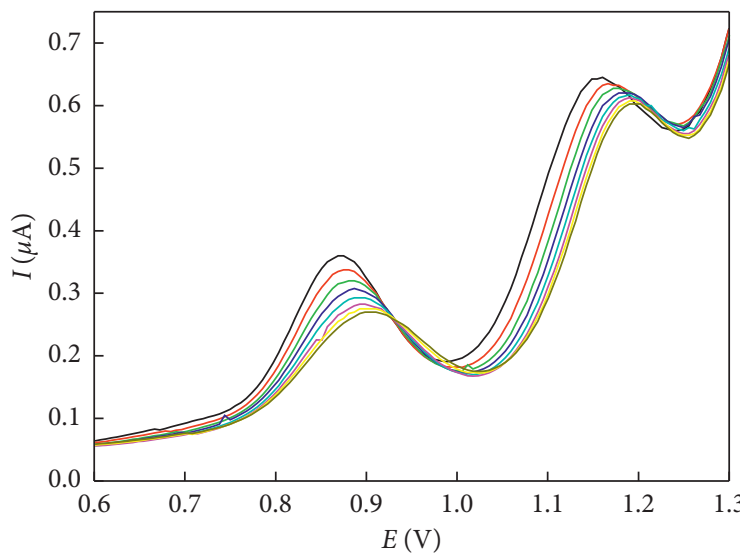

(a)

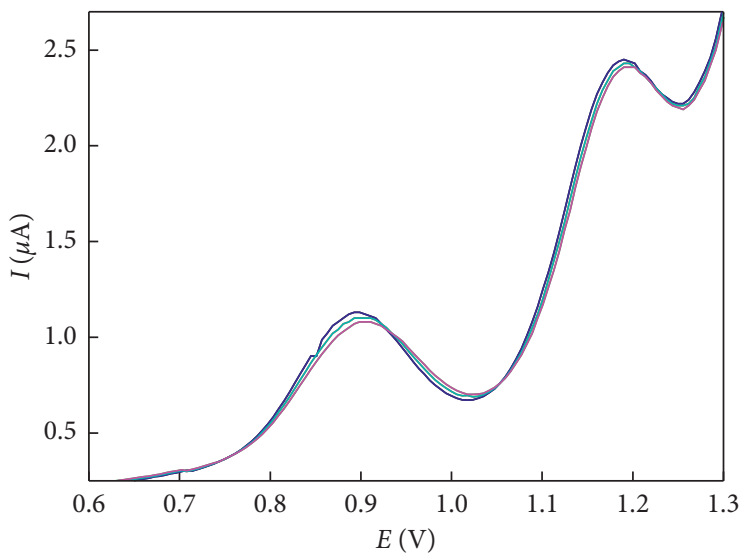

(b)

FIGURE 4: Differential pulse voltammograms for 8 consecutive measurements of $3 \mu \mathrm{g}$ NAP in phosphate buffer at pH 6 using (a) carbon paste electrodes and (b) SWCNTs/CPE. The scan rate employed was $50 \mathrm{mV} \cdot \mathrm{s}^{-1}$. 


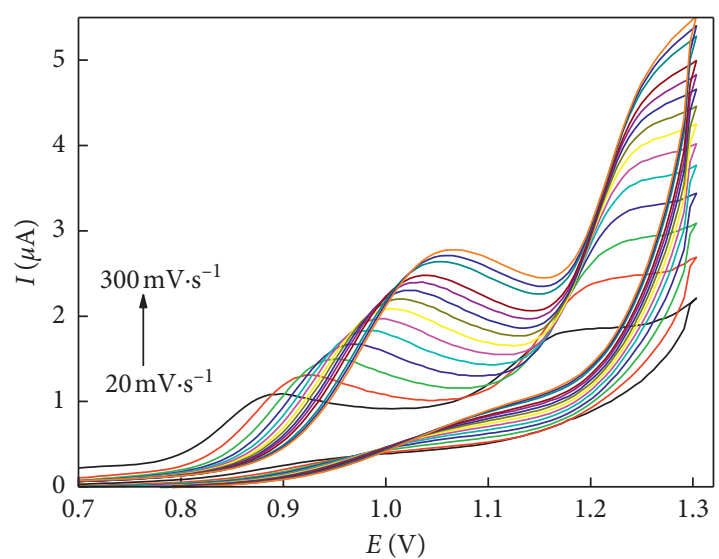

(a)

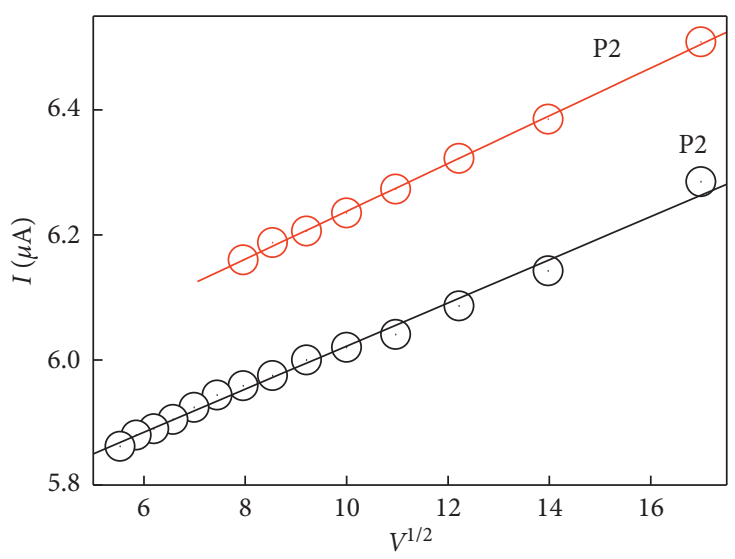

(b)

FIGURE 5: Effect of scan rate on the voltammetric behavior of $3.0 \mu \mathrm{g}$ NAP using SWCNTs/CPE in $2 \times 10^{-1} \mathrm{~mol} \cdot \mathrm{L}^{-1}$ phosphate buffer $\mathrm{pH}$.

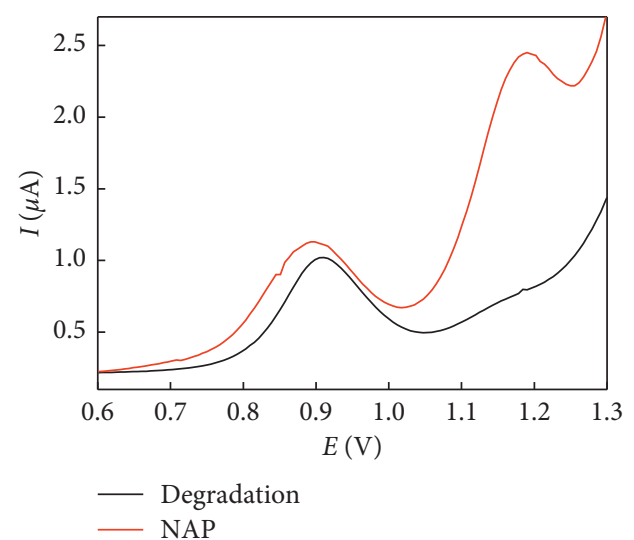

(a)

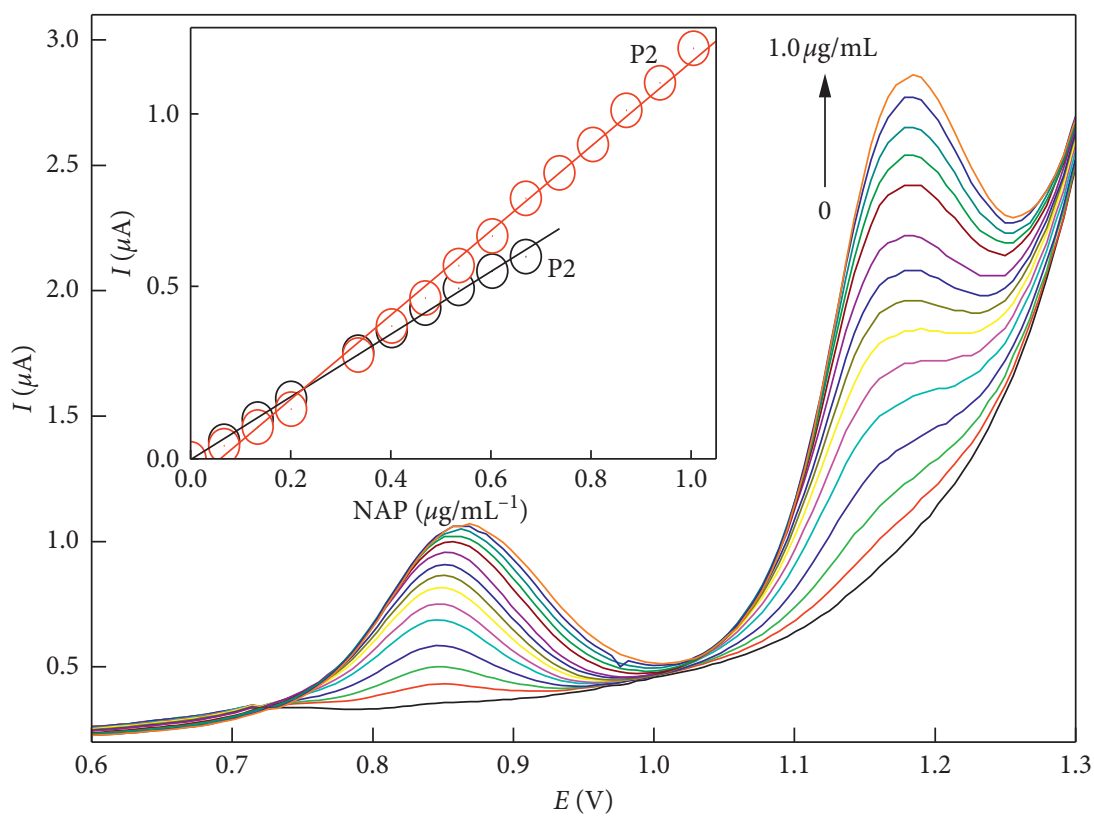

(c)

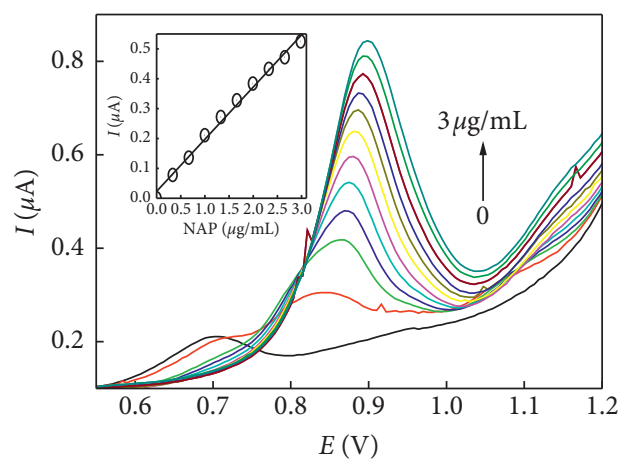

(b) 
TABLE 1: Regression and statistical parameters obtained from differential pulse voltammetry calibration curves of naproxen and its degradation product using SWCNTs/CPE.

\begin{tabular}{lccc}
\hline Parameters & & NAP & Degradation product \\
\hline Concentration range $\left(\mu \mathrm{g} \cdot \mathrm{mL}^{-1}\right)$ & At $0.85 \mathrm{~V}$ & At $1.18 \mathrm{~V}$ & $0.067-0.73$ \\
Slope of regression line $(\mu \mathrm{A})$ & $0.067-0.67$ & $0.067-1.00$ & 0.7696 \\
$s_{\mathrm{a}}(\mu \mathrm{A})$ & 0.9083 & 1.2264 & 0.0096 \\
Intercept of regression line $(\mathrm{b})\left(\mu \mathrm{A} \cdot \mathrm{mL} \cdot \mu \mathrm{g}^{-1}\right)$ & 0.0154 & 0.0321 & 0.0141 \\
$s_{\mathrm{b}}\left(\mu \mathrm{A} \cdot \mathrm{mL} \cdot \mu \mathrm{g}^{-1}\right)$ & 0.0021 & -0.0779 & 0.0043 \\
Correlation coefficient $(r)$ & 0.00626 & 0.0194 & 0.9993 \\
LOD $\left(\mu \mathrm{g} \cdot \mathrm{mL}^{-1}\right)$ & 0.9988 & 0.9956 & 0.045 \\
$\mathrm{LOQ}\left(\mu \mathrm{g} \cdot \mathrm{mL}^{-1}\right)$ & 0.1042 & 0.0812 & 0.135 \\
$\mathrm{SD}$ & 0.31572 & 0.2461 & 0.015 \\
$\mathrm{RSD}(\%)$ & 0.023 & 0.025 & 3.46 \\
\hline
\end{tabular}

TABle 2: Application of the proposed and reference method for the determination of NAP in pure form, dosage form, and plasma.

\begin{tabular}{|c|c|c|c|c|c|c|}
\hline \multirow{2}{*}{$\begin{array}{l}\text { Parameters } \\
\text { Method }\end{array}$} & \multicolumn{2}{|c|}{ Pure form } & \multicolumn{2}{|c|}{ Dosage form } & \multicolumn{2}{|c|}{ Plasma } \\
\hline & $\begin{array}{l}\text { Proposed } \\
\text { method* }^{*}\end{array}$ & $\begin{array}{c}\text { Reference } \\
\text { method [32] }\end{array}$ & $\begin{array}{l}\text { Proposed } \\
\text { method* }^{*}\end{array}$ & $\begin{array}{c}\text { Reported } \\
\text { method [32]* }\end{array}$ & $\begin{array}{l}\text { Proposed } \\
\text { method* }^{*}\end{array}$ & $\begin{array}{c}\text { Reported } \\
\text { method }[32]^{*}\end{array}$ \\
\hline \multirow{3}{*}{$\%$ found } & 102.14 & 101.2 & 100.17 & 100.8 & 96.54 & 97.9 \\
\hline & 100.45 & 100.65 & 100.22 & 99.7 & 97.32 & 99.0 \\
\hline & 99.9 & 99.8 & 99.6 & 98.8 & 98.0 & 99.2 \\
\hline Mean \pm S.D. & $100.83 \pm 1.67$ & $100.55 \pm 0.71$ & $99.99 \pm 0.34$ & $99.77 \pm 1.0$ & $97.28 \pm 0.73$ & $98.7 \pm 0.7$ \\
\hline$t$-test & $0.922(2.776)$ & & $0.876(2.776)$ & & $0.842(2.776)$ & \\
\hline$F$-test & 2.345 (19) & & $1.512(19)$ & & $1.344(19)$ & \\
\hline
\end{tabular}

*Each result is the average of three different separate determinations. Figures in parentheses are the tabulated $t$ and $F$ values, respectively, at $P=0.05$.

variation of the anodic current maxima with the square root of the scan rate were plotted. Linear trend of both oxidation peak currents of NAP vs the root of scan rate $\left(r^{2}\right.$ was 0.999 ) on the working electrode surface was obtained, concluding that the naproxen oxidation process is controlled by diffusion of the electroactive species toward the electrode surface [39], which was reported in a previous report using the MWCNT-modified GCE for NAP detection [27].

\subsection{Determination of Naproxen in Presence of Its Degradation} Product. Marotta et al. [40] reported the photodegradation of naproxen 1-(6-methoxy-2-naphthyl) ethanol and 2acetyl-6-methoxynaphthalene and conversion of the carboxylic group to ethanol and finally ketone, which results in absence of the second oxidation peak. The obtained results were elucidated by performing the IR spectra of NAP and its degradation product (S2).

Naproxen showed two oxidation peaks at $0.85 \mathrm{~V}$ that correspond to naproxen oxidation with the formation of an intermediate carboxylic radical, followed by decarboxylation at $1.18 \mathrm{~V}$ due the formation of ketone (2acetyl-6-methoxynaphthalene, AMN). Upon photodegradation and formation of $A M N$, only the first oxidation peak at $0.890 \mathrm{~V}$ with the disappearance of the second peak was achieved, allowing the simultaneous voltammetric determination of naproxen in presence of its degradation product (Figure 6(a)). The calibration graph for the degradation product was linear in the concentration range 0.067 to $0.73 \mu \mathrm{g} \cdot \mathrm{mL}^{-1}$ with similar slope values to the NAP (Figure 6(b) and Table 1).

At the optimum measuring conditions applying carbon paste electrodes incorporated with $10 \%$ SWCNTs, the standard calibration curves using SWCNT-modified carbon paste electrodes were performed. The peak current at $0.85 \mathrm{~V}$ increased linearly with increasing the NAP in the concentration range 0.067 to $0.67 \mu \mathrm{g} \cdot \mathrm{mL}^{-1}$, while performing calibration at $1.18 \mathrm{~V}$, the calibration graph was linear up to $1.0 \mu \mathrm{g} \cdot \mathrm{mL}^{-1}$ with more reproducibility and sensitivity.

The linearity with regression parameters was calculated according to ICH guidelines (Table 1). The high values of correlation coefficient $(r)$ and low values of standard deviation (SD), standard error (SE), showed the assemblage of the points around the calibration graph and proved the linearity of the method over the specified concentration range.

3.5. Analytical Applications. According to the obtained results, it was possible to apply this technique to the quantitative analysis of NAP in pure form, dosage form, and plasma. The proposed method was successfully applied for the determination of NAP in its pharmaceutical dosage form (Naprosyn tablets; $250 \mathrm{mg}$ NAP/tablet) using SWCNTs/CPEs.

The results obtained by the proposed method were compared with those obtained from the reported method [32] according to $t$-test and $F$-test (Table 2). 
TABLE 3: Comparison of analytical parameters of different naproxen electrodes.

\begin{tabular}{|c|c|c|c|c|c|c|}
\hline Working electrode & $\begin{array}{l}\text { Electrochemical } \\
\text { technique }\end{array}$ & $\begin{array}{c}\text { Linear range } \\
(\mu \mathrm{M})\end{array}$ & LOD $(\mu \mathrm{M})$ & Sample & Degradation product & Reference \\
\hline Glassy carbon electrode & DPV & $10-125$ & 0.3 & Tablets & No & {$[24]$} \\
\hline Boron-doped diamond & DPV & $0.5-50$ & 0.03 & Tablets & Yes & [21] \\
\hline Platinum electrode & DPV & $4.03-108$ & 1.04 & Tablets & No & [19] \\
\hline $\mathrm{ZnO} / \mathrm{MWCNTs} / \mathrm{CPE}$ & SWV & $1.0-200$ & 0.23 & Tablets & No & \\
\hline MWCNTs-Gr-Il/GCE & DPV & $1-100$ & 0.125 & Blood plasma & No & {$[31]$} \\
\hline MWCNTs/GCE & Amperometry & $10-100$ & 0.6 & Tablets & No & [27] \\
\hline Graphite electrode & DPV & $4.9-123$ & 4.45 & Tablets & No & [25] \\
\hline SWCNTs/CPE & DPV & $4.35-65.5$ & 6.255 & Tablets and blood plasma & Yes & Present work \\
\hline
\end{tabular}

To validate the suggested procedure, the linearity, range, limit of detection, limit of quantification, accuracy, and robustness were measured according to the $\mathrm{ICH}$ guidelines.

\section{Conclusion}

In this study, it was shown that carbon paste electrodes modified with carbon nanomaterials can be considered as a sensitive working electrode for simultaneous voltammetric determination of naproxen in presence of its degradation product. From the different method for electrode fabrication, bulk modification with SWCNTs in the PO/CPE showed an effective electrocatalytic activity toward the anodic oxidation of naproxen, which leads to a great increase in the peak current (more than 8 -fold). The present study showed comparable sensitivity with previously published NAP sensors (Table 3 ) with the advantage of simultaneous determination of NAP in presence of its degradation product. The LODs were achieved by the CNT-modified electrode for NAP allowing application of such method for determination of NAP in biological samples without further pretreatment.

\section{Data Availability}

The data used to support the findings of this study are available from the corresponding author upon request.

\section{Conflicts of Interest}

The authors declare that they have no conflicts of interest.

\section{Acknowledgments}

The authors would like to express their gratitude to the National Research Center (project no. 110090360) and National Organization for Drug Control and Research for providing instruments and the means necessary to accomplish this work.

\section{Supplementary Materials}

S1: differential pulse voltammograms for $10.0 \times 10^{-6} \mathrm{~mol} \cdot \mathrm{L}^{-1}$ NAP using silicon oil carbon paste electrodes at different $\mathrm{pH}$ values. S2: FT-IR spectra of naproxen and its degradation product. (Supplementary Materials)

\section{References}

[1] C. S. Boynton, C. F. Dick, and G. H. Mayor, "NSAIDs: an overview," Journal of Clinical Pharmacology, vol. 28, no. 6, pp. 512-517, 1988.

[2] T. Haque, M. M. U. Talukder, S. Laila, K. Fatema, and A. K. L. Kabir, "Simultaneous estimation of naproxen and ranitidine $\mathrm{HCl}$ by using UV spectrophotometer," Stamford Journal of Pharmaceutical Sciences, vol. 1, no. 1, pp. 18-24, 2008.

[3] K. B. Sutradhar, T. Ahmed, A. Ferdous, and R. J. Uddin, "Formulation and comparison of in vitro release profile of hydrophilic and hydrophobic polymer based Naproxen matrix tablets," Journal of Applied Pharmaceutical Science, vol. 1, p. 155, 2011.

[4] P. W. Elsinghorst, M. Kinzig, M. Rodamer, U. Holzgrabe, and F. Sörgel, "An LC-MS/MS procedure for the quantification of naproxen in human plasma: development, validation, comparison with other methods, and application to a pharmacokinetic study," Journal of Chromatography B, vol. 879, no. 19, pp. 1686-1696, 2011.

[5] Y. Sun, Z. Zhang, Z. Xi, and Z. Shi, "Determination of naproxen in human urine by high-performance liquid chromatography with direct electrogenerated chemiluminescence detection," Talanta, vol. 79, no. 3, pp. 676-680, 2009.

[6] A. A. Gouda, M. I. Kotb El-Sayed, A. S. Amin, and R. El Sheikh, "Spectrophotometric and spectrofluorometric methods for the determination of non-steroidal antiinflammatory drugs: a review," Arabian Journal of Chemistry, vol. 6, no. 2, pp. 145-163, 2013.

[7] I. Panderi and M. Parissi-Poulou, "Second-derivative spectrophotometric determination of naproxen in the presence of its metabolite in human plasma," The Analyst, vol. 119, no. 4, pp. 697-701, 1994.

[8] P. Damiani, M. Bearzotti, and M. A. Cabezón, "Spectrofluorometric determination of naproxen in tablets," Journal of Pharmaceutical and Biomedical Analysis, vol. 29, no. 1-2, pp. 229-238, 2002.

[9] G. A. Ibañez and G. M. Escandar, "Combined liquid and solid-surface room temperature fluorimetric determination of naproxen and salicylate in serum," Journal of Pharmaceutical and Biomedical Analysis, vol. 37, no. 1, pp. 149-155, 2005.

[10] J. Sádecká, M. Čakrt, A. Hercegová, J. Polonský, and I. Skačáni, "Determination of ibuprofen and naproxen in tablets," Journal of Pharmaceutical and Biomedical Analysis, vol. 25, no. 5-6, pp. 881-891, 2001.

[11] I. W. Wainer and T. D. Doyle, "Application of highperformance liquid chromatographic chiral stationary phases to pharmaceutical analysis structural and conformational 
effects in the direct enantiomeric resolution of $\alpha$-methylarylacetic acid antiinflammatory agents," Journal of Chromatography A, vol. 284, pp. 117-124, 1984.

[12] A. G. Kazemifard and D. E. Moore, "Liquid chromatography with amperometric detection for the determination of nonsteroidal anti-inflammatory drugs in plasma," Journal of Chromatography B: Biomedical Sciences and Applications, vol. 533, pp. 125-132, 1990.

[13] N. A. El-Maali, "Voltammetric analysis of drugs," Bioelectrochem, vol. 64, no. 1, pp. 99-107, 2004.

[14] S. A. Özkan, B. Uslu, and H. Y. Aboul-Enein, "Analysis of pharmaceuticals and biological fluids using modern electroanalytical techniques," Critical Reviews in Analytical Chemistry, vol. 33, no. 3, pp. 155-181, 2003.

[15] V. K. Gupta, A. Nayak, S. Agarwal, and B. Singhal, "Recent advances on potentiometric membrane sensors for pharmaceutical analysis," Combinatorial Chemistry \& High Throughput Screening, vol. 14, no. 4, pp. 284-302, 2011.

[16] L. Angnes, "Pharmaceuticals and personal care products," in Environmental Analysis by Electrochemical Sensors and Biosensors, pp. 881-903, Springer, Berlin, Germany, 2014.

[17] S. A. Ozkan, J. Kauffmann, and P. Zuman, Electroanalysis in Biomedical and Pharmaceutical Sciences, Springer, Berlin, Germany, 2016.

[18] G. Kanoute, E. Nivaud, B. Paulet, and P. Boucly, "Dosage de derives de l'acide phenylpropionique: a activite pharmacologique par titrage coulometrique," Talanta, vol. 31, no. 2, pp. 144-146, 1984.

[19] N. Adhoum, L. Monser, M. Toumi, and K. Boujlel, "Determination of naproxen in pharmaceuticals by differential pulse voltammetry at a platinum electrode," Analytica Chimica Acta, vol. 495, no. 1-2, pp. 69-75, 2003.

[20] W. T. Fonseca, R. F. Santos, J. N. Alves et al., "Square-wave voltammetry as analytical tool for real-time study of controlled naproxen releasing from cellulose derivative materials," Electroanalysis, vol. 27, no. 8, pp. 1847-1854, 2015.

[21] V. Suryanarayanan, Y. Zhang, S. Yoshihara, and T. Shirakashi, "Voltammetric assay of naproxen in pharmaceutical formulations using boron-doped diamond electrode," Electroanalysis, vol. 17, no. 11, pp. 925-932, 2005.

[22] A. B. Lima, E. O. Faria, R. H. O. Montes et al., "Electrochemical oxidation of ibuprofen and its voltammetric determination at a boron-doped diamond electrode," Electroanalysis, vol. 25, no. 7, pp. 1585-1588, 2013.

[23] A. Afkhami, F. Kafrashi, M. Ahmadi, and T. Madrakian, "A new chiral electrochemical sensor for the enantioselective recognition of naproxen enantiomers using L-cysteine selfassembled over gold nanoparticles on a gold electrode," RSC Advances, vol. 5, no. 72, pp. 58609-58615, 2015.

[24] J. S. Stefano, A. P. d. Lima, R. H. O. Montes, E. M. Richter, and R. A. A. Muñoz, "Fast determination of naproxen in pharmaceutical formulations by batch injection analysis with pulsed amperometric detection," Journal of the Brazilian Chemical Society, vol. 23, no. 10, pp. 1834-1838, 2012.

[25] G. Aguilar-Lira, G. A. Romero, A. Rojas-Hernández, M. PáezHernández, J. Rodríguez-Ávila, and M. J. E. Romero-Romo, "Voltammetric analysis of naproxen in graphite electrodes and its determination in pharmaceutical samples," Electroanalysis, vol. 26, no. 7, pp. 1573-1581, 2014.

[26] G. Y. Aguilar-Lira, G. A. Alvarez-Romero, A. Rojas-Hernandez, M. E. Paez-Hernandez, J. A. Rodriguez-Avila, and M. A. Romero-Romo, "New insights on naproxen quantification using voltammetry and graphite electrodes: development of an optimized and competitive methodology," ECS Transactions, vol. 64, no. 45, pp. 79-89, 2015.

[27] R. H. O. Montes, J. S. Stefano, E. M. Richter, and R. A. A. Munoz, "Exploring multiwalled carbon nanotubes for naproxen detection," Electroanalysis, vol. 26, no. 7, pp. 1449-1453, 2014.

[28] R. H. O. Montes, A. P. Lima, R. R. Cunha et al., "Size effects of multi-walled carbon nanotubes on the electrochemical oxidation of propionic acid derivative drugs: ibuprofen and naproxen," Journal of Electroanalytical Chemistry, vol. 775, pp. 342-349, 2016.

[29] P. Norouzi, F. Dousty, M. R. Ganjali, and P. J. Daneshgar, "Dysprosium nanowire modified carbon paste electrode for the simultaneous determination of naproxen and paracetamol: application in pharmaceutical formulation and biological fluid," International Journal of Electrochemical Science, vol. 4, pp. 1373-1386, 2009.

[30] J. Tashkhourian, B. Hemmateenejad, H. Beigizadeh, M. Hosseini-Sarvari, and Z. Razmi, " $\mathrm{ZnO}$ nanoparticles and multiwalled carbon nanotubes modified carbon paste electrode for determination of naproxen using electrochemical techniques," Journal of Electroanalytical Chemistry, vol. 714715, pp. 103-108, 2014.

[31] K. Sarhangzadeh, "Application of multi wall carbon nanotube-graphene hybrid for voltammetric determination of naproxen," Journal of the Iranian Chemical Society, vol. 12, no. 12, pp. 2133-2140, 2015.

[32] E. Mikami, T. Goto, T. Ohno, H. Matsumoto, and M. Nishida, "Simultaneous analysis of naproxen, nabumetone and its major metabolite 6-methoxy-2-naphthylacetic acid in pharmaceuticals and human urine by high-performance liquid chromatography," Journal of Pharmaceutical and Biomedical Analysis, vol. 23, no. 5, pp. 917-925, 2000.

[33] I. Švancara, K. Vytřas, K. Kalcher, A. Walcarius, and J. Wang, "Carbon paste electrodes in facts, numbers, and notes: a review on the occasion of the 50-years jubilee of carbon paste in electrochemistry and electroanalysis," Electroanalysis, vol. 21, no. 1, pp. 7-28, 2009.

[34] F. Boscá, R. Martínez-Mánez, M. A. Miranda, J. Primo, J. Soto, and L. Vaño, "Oxidative decarboxylation of naproxen," Journal of Pharmaceutical Sciences, vol. 81, no. 5, pp. 479-482, 1992.

[35] S. Inamul-Haque, A. Idrees, and A. Rashid, "Electrochemical behavior of an analgesic," Journal of the Chemical Society of Pakistan, vol. 34, pp. 1266-1273, 2012.

[36] P. A. Todd and S. P. Clissold, "Naproxen a reappraisal of its pharmacology, and therapeutic use in rheumatic diseases and pain states," Drugs, vol. 40, no. 1, pp. 91-137, 1990.

[37] R. J. Chen, Y. Zhang, D. Wang, and H. Dai, "Noncovalent sidewall functionalization of single-walled carbon nanotubes for protein immobilization," Journal of the American Chemical Society, vol. 123, no. 16, pp. 3838-3839, 2001.

[38] J. Zhang, J.-K. Lee, Y. Wu, and R. W. Murray, "Photoluminescence and electronic interaction of anthracene derivatives adsorbed on sidewalls of single-walled carbon nanotubes," Nano Letters, vol. 3, no. 3, pp. 403-407, 2003.

[39] F.-G. Banica, Chemical Sensors and Biosensors: Fundamentals and Applications, John Wiley \& Sons, Hoboken, NJ, USA, 2012.

[40] R. Marotta, D. Spasiano, I. Di Somma, and R. Andreozzi, "Photodegradation of naproxen and its photoproducts in aqueous solution at $254 \mathrm{~nm}$ : a kinetic investigation," Water Research, vol. 47, no. 1, pp. 373-383, 2013. 

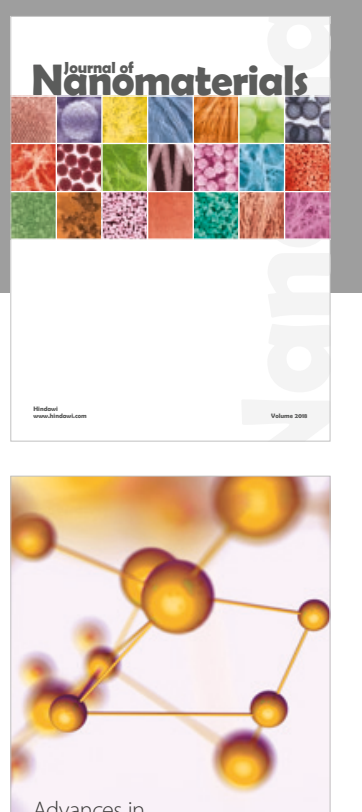

Physical Chemistry
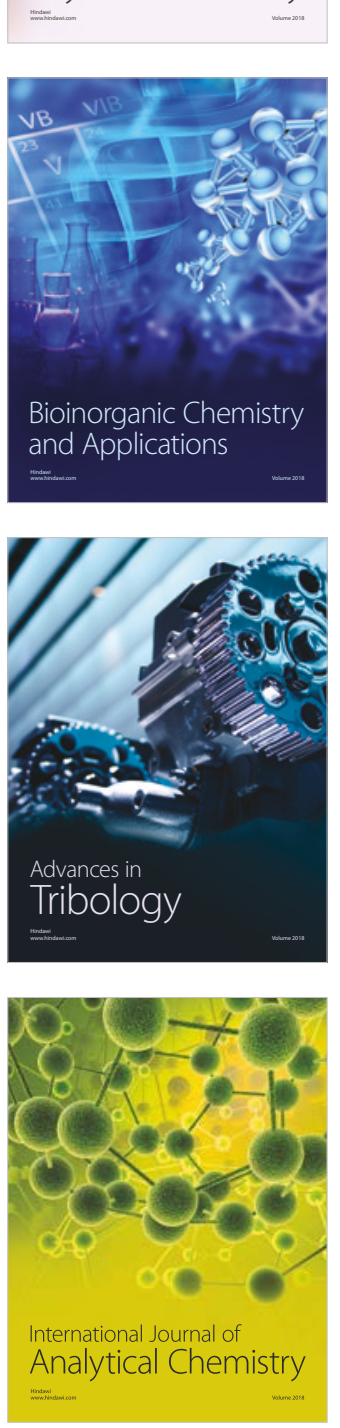

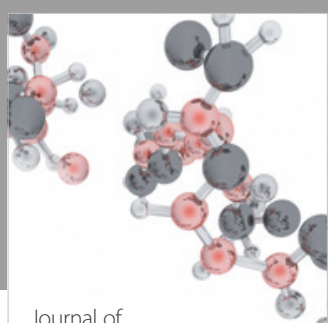

Analytical Methods

in Chemistry

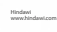

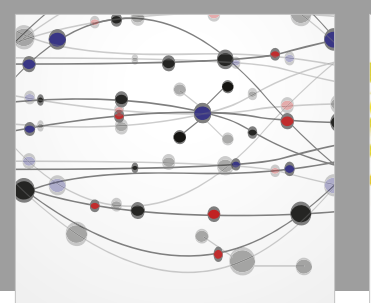

The Scientific World Journal

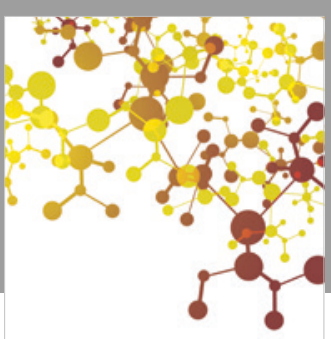

Journal of

Applied Chemistry
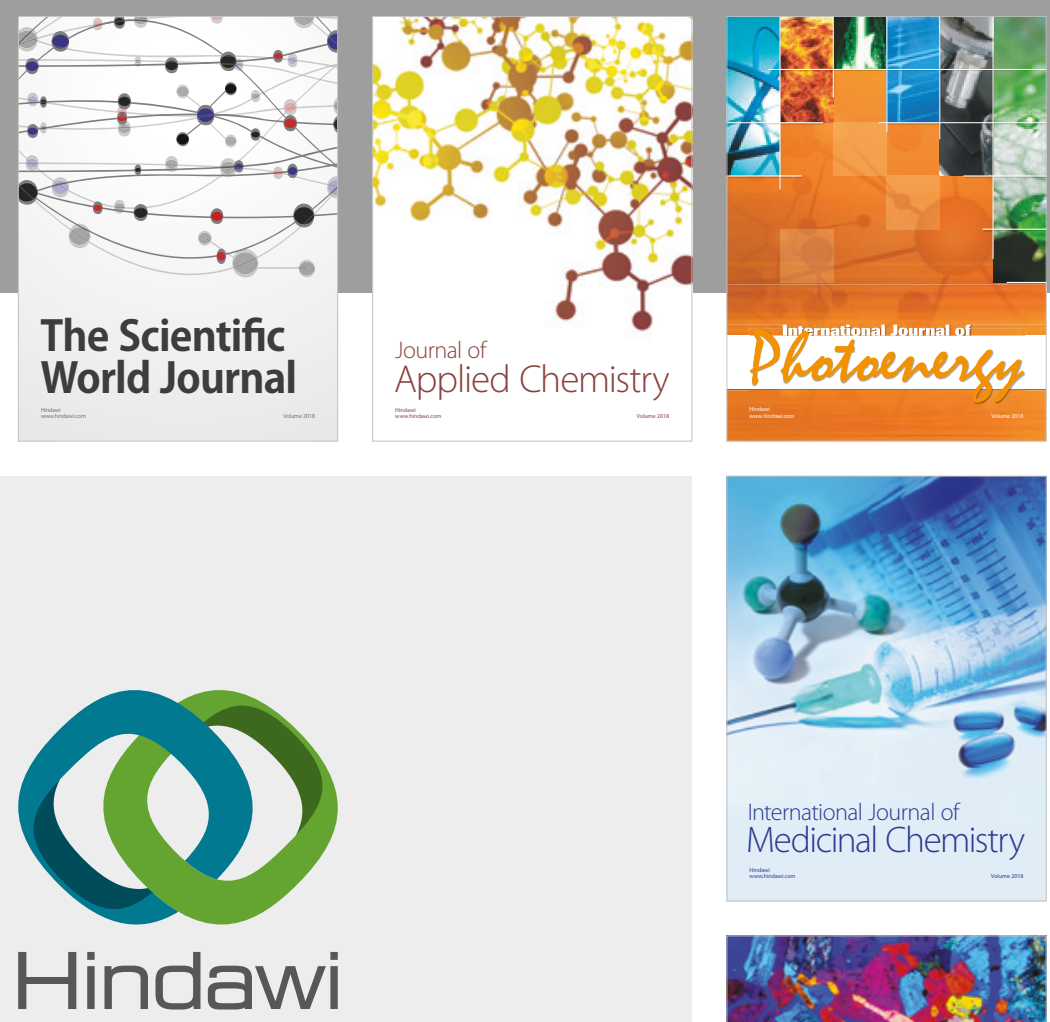

Submit your manuscripts at

www.hindawi.com
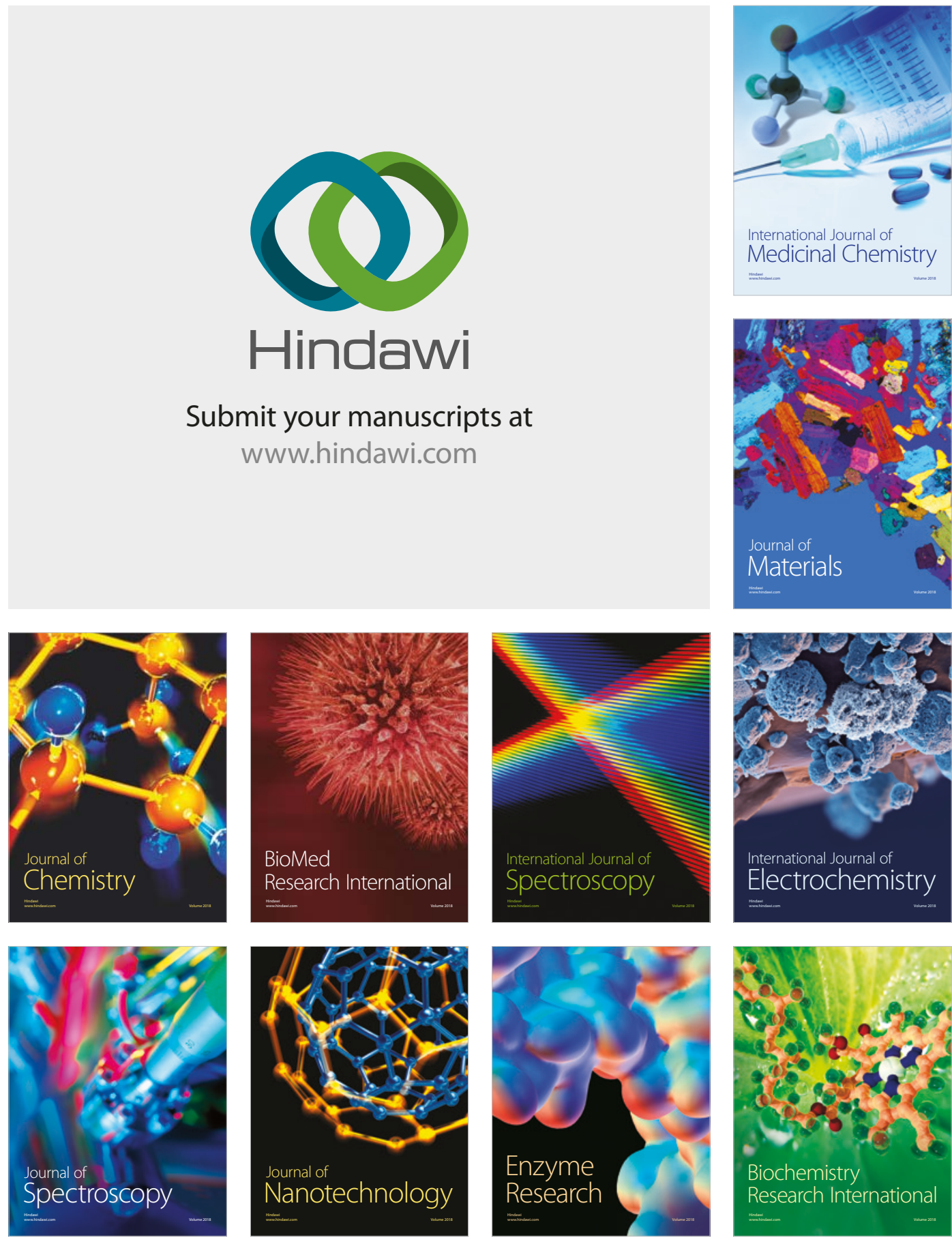
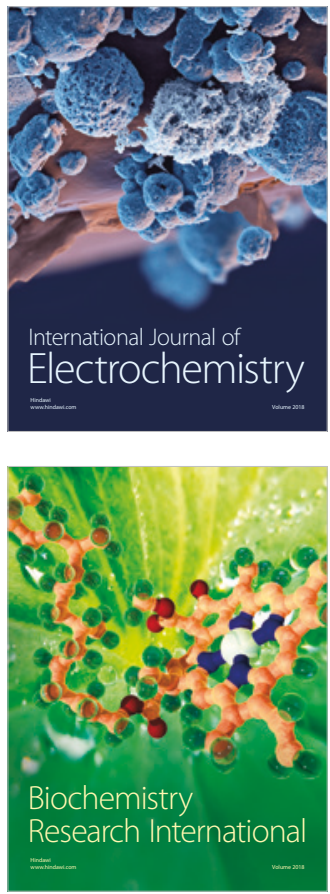